\title{
TRANSPONDO MUROS, CONSTRUINDO RELAÇÕES: UMA REFLEXÃO SOBRE BIBLIOTECAS UNIVERSITÁRIAS E EXTENSÃO NO BRASIL
}

\author{
TRANSPOSING WALLS, BUILDING RELATIONSHIPS: REFLECTIONS ON UNIVERSITY \\ LIBRARIES AND EXTENSION IN BRAZIL
}

Rubens da Silva Ferreira ${ }^{1}$

\section{RESUMO}

Discute sobre algumas ações de extensão das bibliotecas universitárias direcionadas à comunidade externa aos campi. Objetiva refletir sobre a extensão realizada por bibliotecas universitárias no Brasil. Utiliza a pesquisa bibliográfica para a coleta de evidências. Mostra que as bibliotecas universitárias brasileiras têm assumido o papel de agentes em iniciativas de extensão, embora essa ainda seja uma realidade incipiente. Verifica que tais experiências têm privilegiado as ações voltadas para fortalecer o hábito de leitura. Coloca o letramento informacional como outra possibilidade de intervenção bibliotecária. Como conclusão, enfatiza que as bibliotecas universitárias podem mudar o modo como se relacionam com a sociedade por meio da extensão.

\section{PALAVRAS-CHAVE}

Biblioteca universitária. Extensão bibliotecária. Extensão universitária. Brasil.

\section{ABSTRACT}

It discusses the actions of extension of the university libraries directed to the community outside their own campi. It aims to reflect on the extension of university libraries in Brazil. It reveals that the Brazilian's university libraries have assumed the role of agents through these initiatives, though they are still incipient. It shows that such experiences focus on actions dedicated to strength the habit of reading. It puts the information literacy as another possibility for librarian intervention. As conclusion, it is highlighted that the university libraries can change the way how they relate with the society through the extension.

\section{KEYWORDS}

Library extension. University library. University extension. Brazil.

\footnotetext{
${ }^{1}$ M.Sc. em Planejamento do Desenvolvimento (NAEA/UFPA). Esp. em Biblioteca Universitária (CSE/UFPA). Bacharel em Biblioteconomia (CSE/UFPA). Docente e pesquisador da Faculdade de Biblioteconomia. (FABIB/ICSA/UFPA). Vice-Diretor da FABIB/ICSA/UFPA.
} 


\section{INTRODUÇÃO}

Compreender as mudanças pelas quais têm passado a relação entre biblioteca e sociedade desde a segunda metade do século XX implica olhar o processo pelo qual as unidades de informação surgiram na história da humanidade e, também, identificar os sujeitos e/ou grupos sociais aos quais serviam. Assim, em sua gênese, a instituição biblioteca foi construída na Antiguidade para atender os interesses da realeza, quer do ponto de vista administrativo, religioso, científico, econômico, político e cultural. Na passagem para a Idade Média, o dogmatismo da Igreja Católica Apostólica Romana não alterou a relação biblioteca/sociedade, de modo que o acesso aos conteúdos informacionais ainda permanecia resignado a um segmento social que se aproximava dos pergaminhos e dos códices ao optar pela formação nas universitas. Estas, aliás, instituições que deram origem às universidades e às bibliotecas universitárias modernas, oferecendo um acervo mínimo aos estudantes, composto em essência por obras teológicas e filosóficas, o que posteriormente seria alterado pelo aperfeiçoamento da imprensa no século XV.

Nesta perspectiva, ao se levar em consideração a trajetória histórica das bibliotecas universitárias, entende-se que as práticas informacionais têm privilegiado o compromisso com a comunidade acadêmica. As evidências desta escolha são perceptíveis pelos produtos e serviços informacionais orientados para docentes, discentes e pesquisadores, como se as bibliotecas universitárias não fossem sensíveis à comunidade do seu entorno. Assim, partindo desse pressuposto, o presente trabalho busca refletir sobre os caminhos possíveis para uma ação cidadã das bibliotecas vinculadas às universidades brasileiras, procurando responder às questões: quais são as possibilidades que se abrem para as bibliotecas universitárias no século XXI, em direção à construção de uma relação com a sociedade? Como pensar a extensão universitária com uma participação mais ativa das bibliotecas? Na busca de respostas a tais questionamentos, há que se verificarem as evidências tanto na literatura científica quanto nas experiências de aproximação entre bibliotecas universitárias e comunidades.

Por conseguinte, tratadas essas considerações iniciais, a parte seguinte é dedicada aos apontamentos teóricos que ajudam a nortear a reflexão sobre as bibliotecas universitárias do ponto de vista de iniciativas de extensão. Posteriormente, faz-se um esclarecimento sobre o desenho metodológico que orienta o trabalho, o qual é caracterizado como de natureza teórica. Tomando como base algumas iniciativas reais de extensão, tem-se na sequência uma discussão 
sobre como as bibliotecas universitárias se posicionam diante dos serviços levados para as comunidades que vivem em seu entorno. Nesta parte são apontadas, também, outras iniciativas possíveis para além dos projetos de incentivo a leitura, que têm sido muito presentes nas ações extensionistas dessas unidades de informação. Por fim, são apresentadas as considerações finais, em que se vislumbra uma mudança de atitude das bibliotecas universitárias brasileiras no contexto da extensão.

\section{PERSPECTIVA TEÓRICA}

Entender os desdobramentos que culminaram na construção da biblioteca universitária implica um olhar em direção ao passado e mesmo no presente, precipuamente na projeção de cenários possíveis para uma ação cidadã no futuro, orientada para serviços de extensão à comunidade. Neste sentido, Martins (2002) contribui para entender a relação entre biblioteca/sociedade na Antiguidade, na Idade Média e na Idade Moderna. De fato alterações no padrão dessa relação foram viabilizadas no decurso das transformações políticas e culturais que se instalaram nas sociedades em seu movimento histórico. Assim, a inexistência de uma população largamente letrada, a centralização do poder na figura do rei e um Estado onde as funções de chefe político e chefe religioso por vezes se confundiam - ou se complementavam contribuíram durante toda a Antiguidade para a sacralização da biblioteca, o que se sustentou ao longo de toda a Idade Média.

Aliás, no período histórico marcado pelo incontestável domínio da Igreja Católica Apostólica Romana, assiste-se a uma abertura relativa das bibliotecas, mas que beneficiou apenas a aristocracia europeia. Tomando para si a função de instrução baseada no estudo das leis, do latim e dos ensinamentos teológicos, as corporações de mestres e discípulos do século XII denominadas universitas estavam intimamente ligadas à Igreja (DURKHEIM, 1995). Desse modo, o ensino era orientado para a formação moral e erudita do indivíduo, e servia-se de coleções bibliográficas de textos predominantemente religiosos. Somente após a laicização dessas instituições de ensino elas foram paulatinamente cedendo espaço às obras do pensamento filosófico e científico, que vieram a formar os acervos das primeiras bibliotecas universitárias, como a da Sorbonne, de Oxford e da Salamanca. E a partir do século XV, as bibliotecas já reconhecidas em seu papel no contexto das universidades adquiriram as feições que as consolidaram na modernidade, contanto inclusive com um quadro humano formado por 
bibliotecários e sub-bibliotecários (MARTINS, 2002, p. 91).

Muitas foram então as inovações técnicas experimentadas pelas bibliotecas universitárias em sua trajetória até a contemporaneidade. Entre estas se têm a introdução de novos métodos de análise, representação, organização, armazenamento e recuperação de informações que se sucederam à medida que os suportes de fixação do conhecimento humano foram evoluindo. Todavia, nada se compara à introdução da informática combinada às telecomunicações, a qual imprimiu nova dinâmica no ambiente de trabalho dessas organizações. Como explica Castells (1999), essa realidade tecnológica é consequente de um estágio mais avançado do capitalismo, marcado pelo uso intensivo de TIC, em especial pela disseminação e pelo acesso a conteúdos em rede. Esses aspectos são elementares para compreender a noção de sociedade da informação, vista de forma ambivalente por esse autor de tendência marxista, uma vez pode tanto favorecer a circulação global do conhecimento em rede, mas, por outro lado, aprofundar as desigualdades sociais entre indivíduos, grupos e até mesmo entre países ricos e pobres.

É diante dessa realidade ambivalente que as bibliotecas - inclusive as universitárias podem interferir para diminuir os efeitos excludentes que o mercado editorial e tecnológico gera sobre os consumidores de informação de menor poder aquisitivo, em especial os que vivem abaixo da linha pobreza. E ao se pensar especificamente em uma das missões da universidade, a extensão, ou seja, aquela que aproxima essa mistificada instituição produtora de conhecimento da sociedade mais ampla. Lemos e Macedo (1974, p. 172) falam em uma atuação das unidades de informação acadêmicas que ultrapassasse "os limites físicos da universidade". Todavia, a biblioteca universitária aparece nesse discurso apenas como coadjuvante, participando de forma indireta das atividades de extensão por meio da simples disponibilização do acervo aos agentes que efetivamente interagiam com as comunidades, a saber, pesquisadores, professores e estudantes, o que de certa maneira parecia ser suficiente para a própria instituição e para os(as) bibliotecários(as).

Tão frágil quanto a participação das bibliotecas universitárias em ações extensionistas nos anos de 1970 era a própria concepção da extensão, quando de sua introdução no Brasil por ocasião do governo varguista, em $1931^{2}$. Conforme proposto por Francisco Campos no Estatuto da Universidade Brasileira (NOGUEIRA, 2001; FREIRE, 2006), verifica-se que ela emergiu com

\footnotetext{
${ }^{2}$ Conforme Bemvenuti (2006) foi a Universidade Livre de São Paulo, criada em 1912, a primeira a promover ações de extensão com a oferta de palestras semanais gratuitas à comunidade externa.
} 
feições redentoras, como se as classes populares, sem acesso às universidades, pudessem ter sua condição cultural modificada pela elite intelectual benevolente que disseminava seus saberes através de cursos e conferências para a comunidade externa, permanecendo assim durante todo Regime Militar. No entanto, com o processo de abertura democrática, a extensão universitária adquiriu novos rumos, precisamente a partir do "I Encontro Nacional de Pró-Reitores de Extensão das Universidades”, em 1987, que forneceu as diretrizes e as bases conceituais vigentes até os dias atuais.

E ao retomar a participação de bibliotecários(as) é em Vicentini, Martins, Rodrigues, Alves, Ferreira e Truzzi (2007), e em Costa, Motta, Santos e Renault (2008) que se verifica uma alteração no padrão de atuação das bibliotecas universitárias nas ações de extensão acadêmica, permitindo visualizá-las através das iniciativas de um corpo técnico-administrativo que assume o papel de agente nesse processo. Tais autores mostram as possibilidades de engajamento dos profissionais da informação que atuam nessas organizações em atividades de promoção da leitura, palestras e oficinas para a comunidade externa aos campi. Por conseguinte, é sob a ótica de Vicentini, Martins, Rodrigues, Alves, Ferreira e Truzzi (2007) e de Costa, Motta, Santos e Renault (2008) que a análise que se faz busca situar as bibliotecas universitárias como um espaço de cidadania, construído por meio de experiências de extensão planejadas para e com os grupos e sujeitos sem vínculos formais com a Academia, mas que moram no entorno e por vezes possuem acesso precário à informação, sobretudo em função das condições socioeconômicas que marcam a vida cotidiana de parte significativa da população brasileira.

\section{ABORDAGEM METODOLÓGICA}

Fundamentado na reflexão sobre a realidade das bibliotecas universitárias quanto ao envolvimento direto nos serviços de extensão voltados para a comunidade, este estudo situa-se no campo dos de natureza teórica. Assim, ao se buscar respostas às questões anteriormente formuladas, a pesquisa bibliográfica se impõe como instrumento auxiliar, uma vez que consiste em atividade obrigatória na condução de qualquer empreendimento acadêmico, tal como ensina Eco (1991). Por conseguinte, o material de reflexão constitui-se de evidências identificadas em capítulos de livros, trabalhos apresentados em eventos técnico-científicos e artigos de periódico que estruturam os caminhos teóricos do estudo. Desse modo, o material bibliográfico reunido trata de temáticas relacionadas às bibliotecas e à extensão universitária. Por meio dele procurou- 
se construir um corpo coerente de conhecimento, a fim de se vislumbrar direcionamentos possíveis na prestação de serviços à comunidade externa através da extensão, tal como se verá a seguir.

\section{DISCUSSÃO}

O desenvolvimento das sociedades após a Revolução Industrial no século XVIII veio a culminar na especialização do trabalho, cujos efeitos se fazem sentir nos dias atuais com a proliferação de diferentes profissionais e serviços, inclusive no chamado mercado da informação. Essa tendência também se fez refletir nas bibliotecas, planejadas, construídas e equipadas a partir do século XX para atender as necessidades de informação de públicos cada vez mais específicos. No plano teórico, esse processo levou a criação de algumas categorias para designar as unidades de informação de acordo com categorias de usuário. Assim, especializadas, públicas, especiais, escolares, nacionais e universitárias são tipos de bibliotecas classificadas no campo da Biblioteconomia que, em termos didáticos e gerenciais servem para demarcar fronteiras simbólicas sobre até onde essas organizações podem desenvolver suas ações sem invadir os limites de atuação das demais.

Ao se pensar no caso das bibliotecas universitárias, essa tipologia aparentemente bem definida fez os(as) bibliotecários(as) entenderem que seu foco de ação está concentrado especificamente na comunidade acadêmica. Entretanto, a missão institucional da extensão como superação do elo que separa e distancia a universidade da sociedade, o código de ética profissional e a crescente difusão da ideia de informação como recurso de acesso a cidadania tem mostrado que os limites de atuação das bibliotecas vêm se tornando cada vez mais diluídos e interpenetráveis na contemporaneidade. Também, soma-se a isto o quadro socioeconômico das populações dos países em desenvolvimento e subdesenvolvidos, que se vêem no dilema entre satisfazer as necessidades mais básicas ou investir na aquisição dos meios tradicionais - e porque não dizer pós-modernos - de acesso a informação. Logo, para esses segmentos as bibliotecas continuam a ter peso importante como instituições mediadoras de informação. 
Destarte, repensar as bibliotecas universitárias em seu papel social significa descobrir possibilidades de intervenção fundamentadas na extensão. Pois um aspecto entendido como inibidor a uma participação mais efetiva dessas organizações é evidenciado pelo modo como figuram nas ações extensionistas. Em geral elas aparecem nos regimentos institucionais das universidades apenas como elemento de "apoio", portanto, como algo de menor importância dentro do processo de articulação entre o saber técnico-científico e as demandas sociais. Todavia, de forma lenta e progressiva esse panorama vem mudando, felizmente por iniciativa dos(as) próprios(as) bibliotecários(as).

Mesmo que incipientes, os exemplos de algumas bibliotecas universitárias brasileiras devem ser vistos com otimismo, e mesmo interpretados como um sinal de mudança em curso na forma como essas unidades de informação podem se relacionar com a comunidade externa às Instituições de Ensino Superior (IES). Uma das iniciativas mais interessantes é encontrada em Costa, Motta, Santos e Renault (2008), sobre o projeto de criação de um Centro de Extensão para o Sistema de Bibliotecas da Universidade Federal de Minas Gerais. E ainda que tal projeto contemple vários objetivos, merece destaque a articulação pretendida com Organizações NãoGovernamentais (ONG), escolas, hospitais e outras instituições que, colaborativamente, possam contribuir para práticas informacionais cidadãs e de inclusão na sociedade da informação.

A Biblioteca da Universidade Estadual de Campinas (UNICAMP) também já demonstra uma postura ativa no que se refere à realização de ações extensionistas. Realizado desde 2004, o projeto intitulado "Biblioteca Itinerante do Cidadão" foi direcionado para atender a comunidade local e região metropolitana (VICENTINI; MARTINS; RODRIGUES; ALVES; FERREIRA; TRUZZI, 2007). Desenhado por meio de uma parceria entre o Serviço Social Ambulatorial do Hospital de Clínicas e a Biblioteca Central, o público beneficiado pela iniciativa constitui-se de cerca de 4.000 pacientes e acompanhantes, aos quais são oferecidos materiais de leitura com o propósito de contribuir para a humanização no atendimento à saúde. Diante dos resultados alcançados, a coordenação desta ação passou a projetar a ampliação dessa iniciativa e a planejar a aquisição de materiais bibliográficos e equipamentos, bem como a contratação de bolsistas para o fortalecimento desse projeto de efeito duplo. Ou seja, que de um lado contribui para a disseminação da prática da leitura e, por outro, auxilia na construção de um ambiente hospitalar menos tenso para pacientes e acompanhantes. 
Ao que tudo indica, a leitura se faz muito presente nas experiências de extensão universitária levadas a cabo pelas bibliotecas das universidades brasileiras. Outras iniciativas com esse foco que merecem ser citadas são as das bibliotecas setoriais da Universidade Federal do Pará (UFPA). A primeiras delas é de autoria das bibliotecárias Ana Santos e Valdenira Moreira, que em 2003 submeteram o projeto "Bibliobarca: biblioteca para as comunidades ribeirinhas"”3 à Lei nº 6.572/2003 (PARÁ, 2003), conhecida como Lei SEMEAR, que dispõe sobre a concessão de incentivos fiscais aos patrocinadores de projetos culturais no estado do Pará. O objetivo da ação consistiu na aquisição de um barco para a realização de extensão levando a leitura à região conhecida como Baixo Acará - a uma hora de barco de Belém (PA) -, onde vivem diversas comunidades remanescentes de quilombo.

O projeto foi encaminhado pela biblioteca setorial "Prof. José Marcelino Monteiro da Costa", do Núcleo de Altos Estudos Amazônicos da UFPA (NAEA/UFPA) e, apesar de contemplado pela Lei, a proposta não foi executada pela falta de patrocínio para a aquisição da embarcação, o que conduz a uma hipótese sobre a falta de sensibilidade do empresariado local para projetos desse tipo. De todo modo, resta esperar que a iniciativa privada paraense se conscientize de suas responsabilidades sociais para com a realidade amazônica e adote posturas mais cidadãs, em especial no patrocínio aos projetos empreendidos por bibliotecas, quais sejam públicas, escolares, comunitárias ou universitárias.

Outra unidade de informação da UFPA a realizar ações de extensão é a biblioteca "Dr. Alexandre Barros dos Santos", instalada no Hospital Universitário "João de Barros Barreto". Funcionando desde 2003, o projeto "Biblioterapia" é coordenado atualmente pela bibliotecária Roseany Silva e conta com outras atividades além da leitura (CAVALCANTI, 2010). Assim, audição musical, dinâmica de grupo, cessões de cinema e de anedotas são algumas das estratégias empregadas por uma equipe multidisciplinar para promover o bem-estar de internos e acompanhantes em um hospital de alta complexidade, referência estadual em doenças infectocontagiosas. E a despeito de algumas particularidades desse projeto, Cavalcanti (2010) fala da preferência de leitura pelo tema da agricultura familiar, atribuída à origem dos beneficiários, em sua maioria provenientes de municípios de forte economia rural que recorrem a tratamentos de saúde em Belém.

\footnotetext{
${ }^{3}$ Informação fornecida por Valdenira Moreira, em 22 jun. 2010, via e-mail.
} 
Por certo muitas outras podem ser as experiências de extensão implementadas por bibliotecas universitárias no Brasil, as quais se tornam conhecidas entre outras pelos eventos técnico-científicos promovidos em Biblioteconomia, a exemplo do que ocorre no Seminário Nacional de Bibliotecas Universitárias (SNBU). Mas além daquelas que privilegiam a leitura, importa pensar também em outras ações extensionistas, as quais sejam capazes de atender diferentes demandas socioculturais. Nesta direção é possível as bibliotecas universitárias promovendo iniciativas de:

a) Apoio à implantação de bibliotecas comunitárias: num país com proporções territoriais e disparidades sociais como Brasil, muitas podem ser as comunidades atendidas em seu anseio de construir bibliotecas onde crianças, adolescentes e adultos possam ter acesso à cultura por meio de livros, revistas e outros materiais de informação. O desenvolvimento de projetos de extensão para auxiliar essas comunidades coloca-se como da maior importância, especialmente em centros comunitários dos bairros mais afastados dos centros das cidades, nos quais as famílias nem sempre dispõem de recursos financeiros para se deslocarem até elas. Assim, estratégias que envolvam campanhas para a doação de livros, de revistas, de obras de referência (dicionários, almanaques, enciclopédias), de computadores, bem como metodologias para a organização desses materiais de informação e o treinamento de pessoas da comunidade para atuar nessas bibliotecas podem representam contribuições significativas na vida dos moradores dessas comunidades;

b) Oficinas de restauro de acervos em papel e/ou de encadernação: bibliotecas estruturadas com laboratórios de restauro podem pensar em projetos de extensão voltados para a geração de renda na comunidade do entorno da universidade. Ou, ainda, de oficinas de encadernação. Todavia, considerando os custos dos insumos necessários para uma ação de tipo, a capitação de recursos internos ou externos faz-se necessária, assim como a alocação de carga horária para se trabalhar na perspectiva do ensino dessas atividades orientadas para a comunidade externa. Independente da opção escolhida é preciso não perder de vista que a oferta de oficinas dessa natureza pode despertar nos participantes o interesse por uma profissão e mesmo revelar talentos para tais atividades. Ademais, as 
Pró-Reitorias de Extensão das Instituições de Ensino Superior (IES) têm contado cada vez mais com recursos financeiros do governo federal para a implementação de projetos de extensão, o que se coloca como uma oportunidade para as bibliotecas universitárias brasileiras atuarem em contextos de intervenção social;

c) Difusão do patrimônio cultural: na passagem da última década do século XX para o XXI a temática do patrimônio cultural têm adquirido certa visibilidade na sociedade, em especial por estar associada à revitalização da cultura e ao fortalecimento identitário de grupos e de comunidades culturalmente fragilizados ou, no que é mais preocupante, nos casos em que poucos são os atores que detém o saber de um determinado bem cultural, seja uma língua, o conhecimento sobre o modo de produzir alguma coisa (alimento, cerâmica, cestaria, instrumento musical e outros). Como as bibliotecas universitárias são organizações que também se associam à cultura e ao patrimônio bibliográfico e documental, intervenções podem ser feitas no sentido de resgatar as expressões culturais da comunidade em seu entorno, precisamente como forma de preservá-las, documentando-as em textos, fotografias e vídeos, tanto no sentido de preservá-las quanto em direção à socialização destas para a sociedade, utilizando-se inclusive de suas homepages e/ou dos repositórios institucionais quer para o armazenamento como a disseminação desses conteúdos.

Além destas propostas de ação, nas comunidades onde já existem bibliotecas ou salas de leitura, bibliotecários(as) podem desenvolver ações extensionistas baseadas na ideia do chamado letramento informacional (information literacy). Cunhado nos anos de 1970, nos Estados Unidos da América, esse conceito procura expressar o engajamento profissional de pessoas que atuam em práticas educativas nas bibliotecas, as quais são concebidas e desenvolvidas para o aprendizado não apenas de técnicas eficientes de recuperação da informação em diferentes suportes, mas, também, para a crítica sobre as próprias fontes e os conteúdos acessados pelos usuários (DUDZIAK, 2003; CAMPELLO, 2003). O letramento informacional implica, ainda, nas responsabilidades dos indivíduos para com os aspectos éticos que permeiam o acesso e o uso de informações na vida acadêmica, profissional e cotidiana, principalmente sob a perspectiva do potencial desse recurso para a promoção da cidadania. 
Ademais, uma ação orientada para esse tipo de abordagem em escolas públicas dos níveis fundamental e médio de ensino precisa incluir a discussão sobre temas polêmicos relacionados às Tecnologias de Informação e Comunicação (TIC). Iniciativas nessa direção se fazem cada vez mais necessárias, haja vista que a Internet e o telefone celular, por exemplo, têm sido apropriados por grupos e indivíduos para a (re)produção da violência em ambientes digitais ${ }^{4}$. Assim, o ciberbullying ${ }^{5}$, os ataques de rackers, as redes de pedofilia, as comunidades virtuais de ódio e a difamação virtual são evidências de uma realidade que vitimiza principalmente crianças e adolescentes, que utilizam as TIC como inocentes formas de lazer e de sociabilidade. Com efeito, projetos de extensão de bibliotecas universitárias que busquem trabalhar na perspectiva do letramento informacional precisam não só enfatizar a capacitação dos usuários para utilizarem as TIC em seu processo de auto-aprendizado como, também, conscientizá-los sobre as implicações legais, éticas e os riscos que se aplicam a essas ferramentas nas sociedades complexas. Por conseguinte, seja promovendo ações extensionistas de leitura, de biblioterapia, de incentivo à criação de bibliotecas comunitárias ou de letramento informacional, o fundamental é que as bibliotecas universitárias busquem desenvolver estratégias para interferir em uma realidade social brasileira desafiante para os profissionais da informação como os(as) bibliotecários(as).

\section{CONSIDERAÇÕES FINAIS}

As transformações ocorridas a partir da década de 1960 do século XX, que colocaram a informação em evidência na perspectiva do desenvolvimento científico e tecnológico, promoveram alterações significativas no padrão de relação biblioteca/sociedade. Neste sentido, a dinamização dos serviços e dos produtos de informação planejados e executados pelos(as) profissionais bibliotecários(as) tornou-se cada vez mais orientada para os usuários que para a própria instituição biblioteca, historicamente canalizadora do trabalho humano para a formação de coleções com o propósito de reunir e preservar o conhecimento humano escrito. Em linhas

\footnotetext{
${ }^{4}$ A este fenômeno da pós-modernidade expresso de múltiplas formas, autores como Willard (2002), Berson, Berson e Ferron (2002) têm se referido como ciberviolência (cyberviolence), a qual tem sido estuda pelo autor deste trabalho no projeto de pesquisa "A (re)produção da violência no ciberespaço: análise das implicações sociotecnológicas da sociedade da informação".

${ }^{5}$ Entenda-se por cyberbullying como a ação cruel de enviar e publicar material danoso para agredir alguém socialmente através do uso da Internet e/ou outras tecnologias digitais, a exemplo dos telefones celulares (WILLARD, 2005).
} 
gerais, essa alteração é representada pela difusão do paradigma do acesso à informação nas sociedades contemporâneas, o que se opõe ao paradigma dos tempos antigos e medievais, fundamentado no conceito de posse. Desse modo, a onda de mudanças no fazer bibliotecário que se irradia desde o século passado continua a exigir novas estratégias de aproximação com os diferentes segmentos de usuários, sejam estes estudantes dos diferentes níveis de ensino, pesquisadores ou mesmo o cidadão comum.

Como se procurou mostrar na perspectiva das bibliotecas universitárias, uma estratégia possível na aproximação com a sociedade é dada por meio da extensão. Contudo, acredita-se que um dos principais motivos que durante décadas tornaram os(as) bibliotecários(as) invisibilizados(as) nas ações extensionistas reside em uma inserção periférica, institucionalmente expressa pelo discurso universitário da biblioteca como simples elemento de "apoio". Felizmente a difusão de um discurso acadêmico orientado para a cidadania tem contribuído para a mudança de mentalidade e estimulado iniciativas que, embora incipientes, já apontam para os esforços na construção de relações mais próximas com as comunidades que vivem além dos muros das IES. Neste ponto, as experiências em execução ou em vias de se tornarem reais são fundamentais não somente para ampliar a compreensão social do que é a biblioteca universitária e de quem é o profissional bibliotecário. Para além da construção de uma imagem positiva, os projetos de extensão também viabilizam formas de ação mais direcionadas às necessidades sociais de informação dos segmentos populares da sociedade. São empreendimentos desse tipo que permitem situar os(as) bibliotecários(as) como agentes de intervenção numa realidade nacional ainda tão desigual em termos de oportunidades de acesso às TIC, de educação de qualidade, de ampliação do conhecimento e de condições mínimas para uma vida mais cidadã para homens, mulheres e crianças.

\section{REFERÊNCIAS}

BEMVENUTI, V. L. S. Extensão Universitária: momentos históricos de sua institucionalização. Vivências Revista Eletrônica, Erexim, v.1, n. 2, p. 8-17, maio. 2006.

BERSON, I. R.; BERSON, M. J.; FERRON, J. M. Emerging risks of violence in the digital age: lessons for educators from an online study of adolescent girls in United States. Meridian: A Middle School Computer Technologies Journal, Raleigh, v. 5, n. 2, 32 f. 2002. Disponível em: <http://www.ncsu.edu/meridian/sum2002/cyberviolence/>. Acesso em: 19 mar. 2006. 
BRASIL. Ministério da Cultura. Release censo Norte. 2010. Disponível em:

<http://www.cultura.gov.br/site/wp-content/uploads/2010/04/censobmpsnorte2.pdf >. Acesso em: 12 maio 2010.

CAMPELLO, B. O movimento da competência informacional: uma perspectiva para o letramento informacional. Ciência da Informação, Brasília, v. 32, n. 3, p. 28-37, set./dez. 2003.

CASTELLS, M. A sociedade em rede. 4. ed. Rio de Janeiro: Paz e Terra, 1999. v. 1.

CAVALCANTI, A. Leitura faz bem para o corpo. O Liberal, Belém, 16 mar. 2010. Magazine, p. 1.

COSTA, M. E. O.; MOTTA, R. T.; SANTOS, S. A.; RENAULT, L. V.. Proposta de criação de um Centro de Extensão Universitária/Sistema de Bibliotecas UFMG. In: SEMINÁRIO NACIONAL DE BIBLITOECAS UNIVERSITÁRIAS, 15., São Paulo. Anais... São Paulo: USP, 2008. 6 f.

DUDZIAK, E. A. Information literacy: princípios, filosofia e prática. Ciência da Informação, Brasília, v. 32, n. 1, p. 23-35, jan./abr. 2003.

DURKHEIM, E. A revolução pedagógica. Porto Alegre: Artes Médicas, 1995.

ECO, U. Como se faz uma tese. São Paulo: Perspectiva, 1991.

FREIRE, P. Extensão ou Comunicação. 13. ed. São Paulo: Paz e Terra, 2006

LEMOS, A. A. B.; MACEDO, V. A. A. A posição da biblioteca na organização operacional da universidade. Revista de Biblioteconomia de Brasília, Brasília, v. 2, n. 2, p. 167-174, jul./dez. 1974. Disponível em: 〈http://www.tempusactas.unb.br/index.php/RBB/article/viewFile/91/67>. Acesso em: 12 jun. 2010.

MARTINS, W A palavra escrita: história do livro, da imprensa e da biblioteca. 2. ed. São Paulo: Ática, 2002. 519 p.

NOGUEIRA, M. D. P. Extensão Universitária no Brasil: uma revisão conceitual. In: FARIA, D. S. (Org.). Construção Conceitual da Extensão na América-Latina. Brasília, DF: Editora UnB, 2001.

PARÁ. Lei ${ }^{\circ} 5.572$, de 8 de agosto de 2003. Dispõe sobre a concessão de incentivo fiscal para a realização de projetos culturais no Estado do Pará, e dá outras providências. Disponível em:

<http://www.sefa.pa.gov.br/LEGISLA/leg/estadual/ICMS/Lei6572-03.htm>. Acesso em: 27 maio 2010. 
VICENTINI, L. A.; MARTINS, V. S. G.; RODRIGUES, C. A.; ALVES, A. D.; FERREIRA, D. T.; TRUZZI, M. O papel da biblioteca universitária no incentivo à leitura e promoção da cidadania. Biblos: Revista de Bibliotecología y Ciências de la Información, Lima, n. 27, v. 8, p. 1-9, enero-marzo, 2007. Acesso em: 23 abr. 2010. Disponível em:

<http://redalyc.uaemex.mx/redalyc/pdf/161/16102706.pdf >. Acesso: 12 jun. 2010.

WILLARD, N. Educator's guide to cyberbullying and cyberthreats. 2005. Disponível em: <http://www.cyberbully.org/cyberbully/docs/cbcteducator.pdf> $>$. Acesso em: 7 maio 2010. 